\section{Evaluation of Resistance to Gummy Stem Blight in a Population of Recombinant Inbred Lines of Watermelon $\times$ Citron}

\author{
Luis A. Rivera-Burgos \\ Department of Crop and Soil Sciences, North Carolina State University, \\ Raleigh, NC 27695-7609
}

Emily Silverman

Department of Horticultural Science, North Carolina State University, Raleigh, NC 27695-7609

Nebahat Sari

Department of Horticulture, Cukurova University, 01330, Adana, Turkey

Todd C. Wehner

Department of Horticultural Science, North Carolina State University, Raleigh, NC 27695-7609

Additional index words. disease severity, fruit quality, PCA analysis, segregation, Stagonosporopsis cucurbitacearum

\begin{abstract}
Gummy stem blight (GSB), a major disease caused by Stagonosporopsis cucurbitacearum (syn. Didymella bryoniae), has caused significant losses of watermelon in the United States. The lack of progress in the development of resistant cultivars is the result of complex inheritance of resistance and breeding strategies that rely on singleplant selection. Because the sources of resistance are wild watermelon relatives, good fruit quality has been difficult to maintain during the selection process. Three hundred recombinant inbred line (RILs) in a population that carries resistance genes to GSB as well as good fruit quality were produced. This was accomplished by crossing and intercrossing resistant plant introductions, crossing the resulting progenies with elite cultivars, intercrossing those progenies, and, finally, self-pollinating to the $S_{3}$ generation. The 300 RILs were evaluated for disease severity and fruit morphological and quality traits under greenhouse and field conditions in a randomized complete block design with 10 replications and 3 years. The means and correlations for disease severity ratings and fruit quality traits were estimated. Approximately 186 RILs had disease severity ratings below the mean value of the disease assessment scale (4.5), indicating that they possibly carry one or more genes for resistance to GSB. All disease severity ratings were correlated to each other $(r=0.67-0.98 ; P<0.001)$, but they were not correlated with fruit quality traits. Most importantly, several resistant RILs showed good to excellent fruit quality. Our results provide evidence of improved germplasm with high resistance and good fruit quality.
\end{abstract}

Gummy stem blight (GSB) is a major disease of watermelon [Citrullus lanatus (Thunb.) Matsum. \& Nakai] that leads to

Received for publication 1 Dec. 2020. Accepted for publication 15 Jan. 2021.

Published online 15 February 2021.

This research was conducted as part of the CucCAP Project supported by United States Department of Agriculture and by the North Carolina Agricultural Research Service.

We thank D. Wisnowski, D. Reiland, G. Bolyard, and C. Gantt for assistance with the field and greenhouse work. We also thank the personnel at the Horticultural Crops Research Station, Clinton, $\mathrm{NC}$, for assistance with the field work.

L.A.R.-B. is the corresponding author. E-mail: lariver2@ncsu.edu.

This is an open access article distributed under the CC BY-NC-ND license (https://creativecommons. org/licenses/by-nc-nd/4.0/). watermelon-producing countries (Basim et al., 2016; Huang and Lai, 2019). Currently, GSB on watermelon plants is as evident as crown blight, stem cankers, and extensive defoliation, with symptoms observed on the cotyledons, hypocotyls, leaves, and fruit (Maynard and Hopkins, 1999). S. cucurbitacearum is seed-borne (Lee et al., 1984), airborne (van Steekelenburg, 1983), and soil-borne (Bruton, 1998).

Adequate control of GSB through fungicide applications (Keinath, 2016) and appropriate cultural practices (dos Santos et al., 2016; Keinath, 1996) is difficult, particularly during rain, when relative humidity remains high for extended times (Café-Filho et al., 2010). In addition, there is concern among pathologists regarding the development of resistance to fungicides by $S$. cucurbitacearum (Avenot et al., 2012; Li et al., 2016; Thomas et al., 2012). Resistance to GSB has received attention since the 1970 s as a possible alternative to chemical control (Lou et al., 2013; Norton et al., 1986, 1993, 1995).

In previous studies, PI 189225 was identified as the most resistant accession in the U.S. Department of Agriculture Agricultural Research Service (USDA-ARS) watermelon germplasm collection (Sowell and Pointer, 1962). Later, PI 271778, PI 500335, PI 505590, PI 512373, PI 164247, and PI500334 were also identified as accessions resistant to GSB (Boylan et al., 1994). When resistant PI 189225 was crossed with susceptible Charleston Gray, a single recessive gene $(d b / d b)$ controlling the resistance was identified (Norton, 1979). To develop resistant cultivars with a high yield of high-quality fruit, PI 189225 and PI 271778 were chosen as resistant parents in crosses with 'Crimson Sweet' and 'Jubilee'. Several lines with moderate resistance to GSB were released as 'AU-Jubilant', 'AU-Producer' (Norton et al., 1986), ‘AU-Golden Producer' (Norton et al., 1993), and 'AU-Sweet Scarlet' (Norton et al., 1995). However, they were much less resistant to GSB than the resistant parents PI 189225 and PI 271778. In cucumber, it was found that genetic factors were weaker than environmental factors, and that there were five genes controlling resistance (St. Amand and Wehner, 2001). Recently, watermelon accessions with GSB resistance, PI 189225, PI 482283, and PI 526233, were crossed with susceptible cultivars, and their progeny showed a continuous distribution of the disease phenotype and partial failure of the data to fit the single gene inheritance. Therefore, resistance to GSB in PI 189225, PI 482283, and PI526233 may be controlled by a more complex genetic system (Gusmini et al., 2017).

Additional sources of resistance to and variations in fungicide effectiveness against GSB in watermelon have been reported (Gusmini et al., 2005; Li and Brewer, 2016). Additionally, an efficient screening method has been developed for identifying resistant germplasm (Song et al., 2004), including a system for the mass production of inoculum of $S$. cucurbitacearum for large field screening experiments (Gusmini et al., 2003). Available plant introduction 
Table 1. Plant material and breeding approach.

\begin{tabular}{|c|c|c|}
\hline Generation & Breeding approach & Description \\
\hline \multirow[t]{6}{*}{$\mathrm{I}_{0}$} & PI $482342 \times$ PI 482283 & \multirow[t]{6}{*}{ Crosses of the most resistant plant introductions } \\
\hline & PI $482342 \times$ PI 189225 & \\
\hline & PI $189225 \times$ PI 482342 & \\
\hline & PI $482374 \times$ PI 189225 & \\
\hline & PI $526233 \times$ PI 482283 & \\
\hline & PI $526233 \times$ PI 189225 & \\
\hline \multirow{3}{*}{$\begin{array}{l}\mathrm{I}_{1} \\
\mathrm{I}_{2} \\
\mathrm{I}_{3}\end{array}$} & Four cycles of intercrossing & \multirow[t]{3}{*}{ Intercrossing without selection } \\
\hline & & \\
\hline & & \\
\hline \multirow[t]{7}{*}{$\mathrm{I}_{4} \mathrm{~F}_{0}$} & Charleston Gray & \multirow{7}{*}{$\begin{array}{l}\text { Crossing with susceptible elite lines of excellent } \\
\text { fruit quality }\end{array}$} \\
\hline & Calhoun Gray & \\
\hline & Mickylee & \\
\hline & Minilee & \\
\hline & Allsweet & \\
\hline & Crimson Sweet & \\
\hline & Petite Sweet & \\
\hline \multirow{4}{*}{$\begin{array}{l}\mathrm{I}_{4} \mathrm{~F}_{1} \mathrm{I}_{1} \\
\mathrm{I}_{4} \mathrm{~F}_{1} \mathrm{I}_{2} \\
\mathrm{I}_{4} \mathrm{~F}_{1} \mathrm{I}_{3} \\
\mathrm{I}_{4} \mathrm{~F}_{1} \mathrm{I}_{4}\end{array}$} & Four cycles of intercrossing & \multirow{4}{*}{$\begin{array}{l}\text { Intercrossing without selection while } \\
\text { maintaining wild and elite types in the population }\end{array}$} \\
\hline & & \\
\hline & & \\
\hline & & \\
\hline $\mathrm{I}_{4} \mathrm{~F}_{1} \mathrm{I}_{4} \mathrm{~S}_{1}$ & Seven cycles of self- & Self-pollination of plants at random to \\
\hline $\mathrm{I}_{4} \mathrm{~F}_{1} \mathrm{I}_{4} \mathrm{~S}_{2}$ & pollination & develop recombinant inbred lines \\
\hline $\mathrm{I}_{4} \mathrm{~F}_{1} \mathrm{I}_{4} \mathrm{~S}_{3}$ & & \\
\hline $\begin{array}{l}\mathrm{I}_{4} \mathrm{~F}_{1} \mathrm{I}_{4} \mathrm{~S}_{4} \\
\mathrm{I}_{4} \mathrm{~F}_{1} \mathrm{I}_{4} \mathrm{~S}_{5}\end{array}$ & & \\
\hline $\begin{array}{l}{ }_{4} \mathrm{~F}_{1} \mathrm{I}_{4} \mathrm{~S}_{5} \\
\mathrm{I}_{4} \mathrm{~F}_{1} \mathrm{I}_{4} \mathrm{~S}_{6}\end{array}$ & & \\
\hline $\mathrm{I}_{4} \mathrm{~F}_{1} \mathrm{I}_{4} \mathrm{~S}_{7}$ & & \\
\hline
\end{tabular}

$\mathrm{I}=$ intercrossing; $\mathrm{F}_{1}=$ filial $1 ; \mathrm{S}=$ self-pollination.

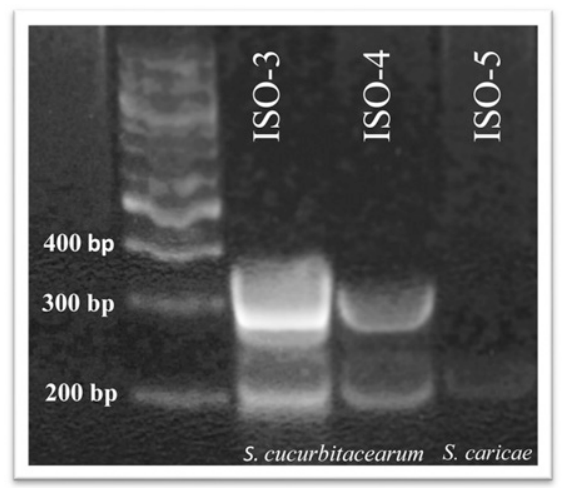

Fig. 1. Genetic identification of isolate number 3 (ISO-3) as $S$. cucurbitacearum causing gummy stem blight in cucurbit crops (Brewer et al., 2015). ISO-4 and ISO-5 were other isolates used as controls.

accessions (total of 1274 accessions) from the USDA-ARS watermelon germplasm collection, along with 51 cultivars, were tested to identify new sources of resistance to GSB (Gusmini et al., 2005). A total of 59 accessions that were at least as good as PI 189225 and PI 271778 were identified in field and greenhouse tests. Two of the best were PI 482283 and PI 526233.

Resistance to pathogens can be qualitative or quantitative. However, quantitative resistance requires more time and resources because inheritance is complex and the levels of resistance often are less distinct. Because efforts to transfer a single gene for resistance to adapted cultivars were not successful, we used a different approach. Resistant acces- sions were intercrossed multiple times before crossing progenies from advanced cycles to adapted cultivars. After that, we crossed and intercrossed progeny from resistant $\times$ elite for multiple cycles. We hoped to improve our chances of transferring resistance genes from Citrullus amarus to C. lanatus.

We used the rating method for GSB resistance created by Gusmini et al. (2002). The scale for leaves and stems was as follows: $0=$ no disease; $1=$ yellowing on leaves (a trace of disease only); 2 to $4=$ symptoms on leaves only; $5=$ some leaves dead, no symptoms on stem; 6 to $8=$ symptoms on leaves and stems; and $9=$ plant dead. The scale was used for screening accessions from the watermelon germplasm collection for resistance to GSB (Gusmini et al., 2005). The scale has been used in genetic analyses of large numbers of plants tested in multiple environments (Gusmini et al., 2017). Another method of measuring disease severity involves the area under the disease progress curve (AUDPC). The AUDPC is a measure of quantitative disease resistance that uses data from repeated ratings (Schandry, 2017; Simko and Piepho, 2012; Yuen and Forbes, 2009). This assessment of disease severity summarizes disease progress over time with a single value (Schandry, 2017; Yuen and Forbes, 2009). We used those rating methods to ranking resistant and susceptible cultigens (Gusmini et al., 2017; Schandry, 2017).

In addition to high resistance to GSB, we were interested in retaining as much external and internal fruit quality characteristics as possible for use in watermelon breeding (Haejeen et al., 2010). Some descriptors are used for morphological characterization of watermelon (Szamosi et al., 2009). However, because the number of morphological characteristics in watermelon is high, the minimum descriptor list is used in breeding studies. Fruit shape is an important characteristic to consider because of the different market requirements. Generally, fruit shape categories are elongate, round, or oval, and the genetic basis is one gene involving the round or elongate shape, with the $F_{1}$ being intermediate (Wehner, 2008). Similarly, rind pattern and toughness (durability) are important characteristics of watermelon fruit. Rind patterns can be gray, striped, or solid, and rind stripes can be narrow, medium, or wide (Gusmini and Wehner, 2006). Good rind durability (toughness) is important for reducing losses due to shipping damage. Ideally, the rind should be thick and tough on largefruited cultivars, but a thin and tough rind is desirable on small-fruited cultivars. In general, the thickness should be a small percentage of the flesh diameter to obtain the maximum edible volume. Rind toughness can be measured by driving a spring-loaded punch into the rind, dropping the fruit onto the ground from the height of the knees to determine whether it breaks, and using the "thumb" test, which involves the breeder pressing on the rind (Wehner, 2008). The flesh color of watermelon fruit is an important trait for consumers. Flesh color can be scarlet red, coral red, orange, canary yellow, salmon yellow, or white (Zhang et al., 2017). Scarlet red $\left(Y^{S c r} Y^{S c r}\right)$ is dominant to coral red $\left(Y^{C r l} Y^{C r l}\right)$, which is dominant to orange $\left(y^{o} y^{o}\right)$, which is dominant to salmon yellow $(y y)$. Canary yellow $(C C)$ is dominant to noncanary yellow $(c c)$ and epistatic to (overcomes) the $y$ locus for scarlet red-coral and redorange-salmon yellow. Coral red is recessive to the white flesh color that is common in citron. Additionally, the seed color and size of watermelon fruit are important for the market. Seed color can be white, tan, brown, black, red, green, or dotted. Seed size can be tomato, small, medium, or large. Black seed color is the most attractive with scarlet red or canary yellow flesh color (Wehner, 2008).

The objective of this study was to evaluate an RIL population and starting materials of watermelon $(C$. lanatus subsp. lanatus $\times C$. lanatus var. citroides) for resistance to GSB and fruit quality traits. We aimed to combine resistance genes from PI accessions from several cycles of intercrossing with highquality fruit from susceptible cultivars to identify lines for cultivar development.

\section{Materials and Methods}

Plant material. The GSB watermelon breeding population was developed by intercrossing the most GSB-resistant plant introduction accessions of Citrullus lanatus var. citroides (PI 482342, PI189225, PI482374, PI526233, and PI482283) four times $\left(\mathrm{I}_{4}\right)$, followed by crossing with elite cultivars of watermelon Citrullus lanatus subsp. lanatus (Charleston Gray, Calhoun Gray, Mickylee, Minilee, Allsweet, Crimson Sweet, and Petite Sweet; $\mathrm{I}_{4} \mathrm{~F}_{1}$ ), followed by intercrossing 


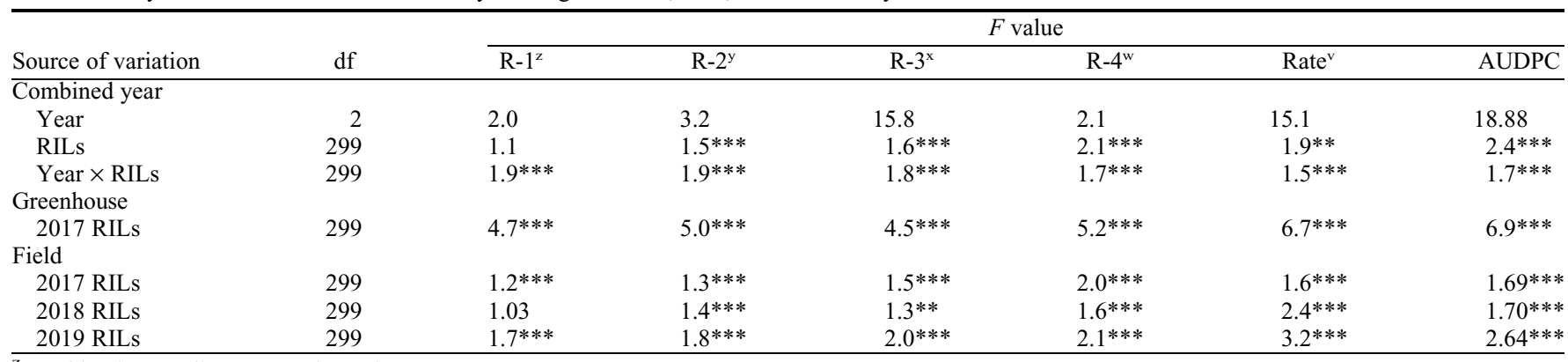

${ }^{\mathrm{z}}$ Combined years disease severity rating at 7 DAI.

${ }^{\mathrm{y}}$ Combined years disease severity rating at 14 DAI.

${ }^{\mathrm{x}}$ Combined years disease severity rating at 21 DAI.

${ }^{\mathrm{w}}$ Combined years disease severity rating at 28 DAI.

${ }^{\mathrm{v}}$ Combined years disease severity rating.

$\mathrm{AUDPC}=$ area under the disease progress curve; $\mathrm{RIL}=$ recombinant inbred line; $\mathrm{DAI}=$ days after inoculation.

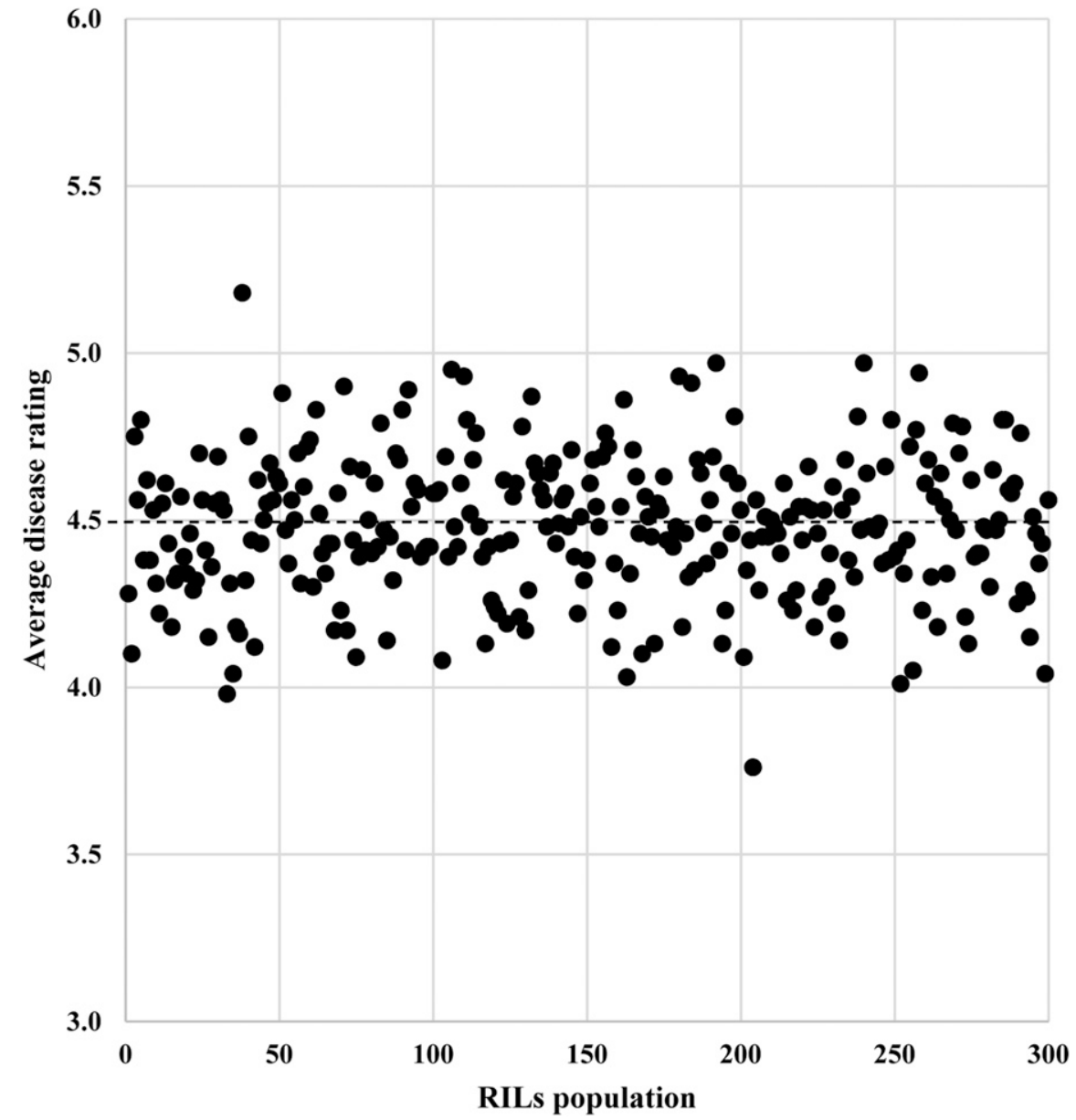

Fig. 2. Average disease ratings (rate) of 300 recombinant inbred lines (RILs). The black dots represent the combined year mean value of ratings. Black dotted line indicates the mean value of the disease assessment scale (4.5).

without selection while maintaining wild and elite types in the population $\left(\mathrm{I}_{4} \mathrm{~F}_{1} \mathrm{I}_{4}\right)$, followed by self-pollination of plants at random $\left(\mathrm{I}_{4} \mathrm{~F}_{1} \mathrm{I}_{4} \mathrm{~S}_{3}\right)$ to develop 300 RILs (Table 1). The 300 RILs were evaluated in two locations (greenhouse and field) during 2017 and 2018, and in the field in 2019. Additionally, 12 accessions (PI 169286, PI 183398, PI 189225, PI 195771, PI 247398, PI 279461, PI 357678, PI 482284, PI 482315, PI 508443, PI 512398, and PI 526233) and 8 cultivars (Allsweet, Calhoun Gray, AU-Producer, Mickylee, Sugar Baby, Charleston Gray, Black Diamond, and $\mathrm{NH}$ Midget) were planted as controls in both locations.

Planting and management. The experiments were conducted in greenhouses at North Carolina State University in Raleigh, $\mathrm{NC}$, and in the field at the Horticultural Crops Research Station at Clinton, NC, during the
Summer 2017, Summer 2018, and Summer 2019 . In the greenhouse, temperatures ranged from 23 to $43^{\circ} \mathrm{C}(0800-2000 \mathrm{HR})$ and from 12 to $24{ }^{\circ} \mathrm{C}(2000-0800 \mathrm{HR})$ when the assays were performed. Seeds were directly sown into 18 -cell plastic trays $(82.6 \times 82.6 \times$ $79.4 \mathrm{~mm}$ size) filled with a soilless mix (Canadian sphagnum peatmoss, perlite, vermiculite, processed pine bark). Two seeds per cell were sown and, after germination, thinned to one to ensure a uniform experiment. In the field, seeds were sown on raised, shaped beds on 3.1-m centers in single hills $1.2 \mathrm{~m}$ apart and covered with black plastic mulch. Fertilizer and water were provided via drip irrigation tubes under the plastic. The fields were culturally managed in accordance with North Carolina recommendations (Kemble et al., 2020)

Inoculum preparation. The isolate of $S$. cucurbitacearum was originally obtained from diseased cucumber tissues harvested from naturally infected plants in the field in 1998. During Fall 2001, we reisolated $S$. cucurbitacearum from watermelon plants that were artificially inoculated with the isolate and developed a new stock of inoculum from single spores. Pycnidia were identified with a dissecting microscope $(20 \times)$ and transferred to petri plates containing potato dextrose agar (PDA; $25 \mathrm{~mL} /$ petri plate). Isolates were selected from the first subculture on PDA based on the following macroscopic observations: colonies that were dark in color and that showed concentric circles of growth were kept and transferred to fresh PDA. Cultures that did not appear contaminated by other fungi or bacteria were transferred to a medium containing $25 \%$ PDA to stimulate abundant sporulation. We observed pycnidia/pseudothecia and spores to verify that their shape and size matched those of $S$. cucurbitacearum (Zitter and Thomas, 1996).

Genomic DNA of GSB isolates collected from field outbreaks was extracted and a polymerase chain reaction-based marker test was performed to genetically identify $S$. cucurbitacearum (syn. Dydymella bryoniae) causing GSB in cucurbit crop fields. We used three sets of primers, including Db05 that 
Table 3. Means of disease severity in the greenhouse, field, and combined years.

\begin{tabular}{|c|c|c|c|c|}
\hline Trait & Mean & SD & Min. & Max. \\
\hline \multicolumn{5}{|c|}{ Combined year } \\
\hline $\mathrm{R}-1^{\mathrm{z}}$ & 2.7 & 0.2 & 2.2 & 3.5 \\
\hline $\mathrm{R}-2^{\mathrm{y}}$ & 4.1 & 0.2 & 3.5 & 4.9 \\
\hline$R-3^{x}$ & 4.9 & 0.3 & 4.1 & 5.6 \\
\hline $\mathrm{R}-4^{\mathrm{w}}$ & 6.2 & 0.3 & 5.0 & 7.0 \\
\hline Rate $^{\mathrm{v}}$ & 4.5 & 0.2 & 3.8 & 5.2 \\
\hline AUDPC & 94.3 & 4.4 & 78.6 & 107.7 \\
\hline \multicolumn{5}{|l|}{ Greenhouse } \\
\hline $\mathrm{R}-1^{\mathrm{z}}$ & 3.3 & 0.6 & 1.5 & 4.6 \\
\hline $\mathrm{R}-2^{\mathrm{y}}$ & 4.7 & 0.7 & 3.0 & 6.5 \\
\hline$R-3^{x}$ & 5.6 & 0.8 & 3.1 & 7.7 \\
\hline $\mathrm{R}-4^{\mathrm{w}}$ & 6.1 & 0.9 & 3.7 & 8.1 \\
\hline Rate $^{v}$ & 4.8 & 0.7 & 3.1 & 6.1 \\
\hline AUDPC & 102.8 & 14.4 & 64.9 & 128.9 \\
\hline \multicolumn{5}{|l|}{ Field 2017} \\
\hline $\mathrm{R}-1^{\mathrm{z}}$ & 2.1 & 0.2 & 1.4 & 3.6 \\
\hline $\mathrm{R}-2^{\mathrm{y}}$ & 3.5 & 0.3 & 2.7 & 4.5 \\
\hline$R-3^{x}$ & 3.9 & 0.4 & 3.0 & 5.3 \\
\hline $\mathrm{R}-4^{\mathrm{w}}$ & 5.1 & 0.5 & 3.7 & 7.2 \\
\hline Rate $^{\mathrm{v}}$ & 3.7 & 0.3 & 2.9 & 4.8 \\
\hline AUDPC & 76.6 & 6.3 & 60.9 & 99.7 \\
\hline \multicolumn{5}{|l|}{ Field 2018} \\
\hline $\mathrm{R}-1^{\mathrm{z}}$ & 1.8 & 0.2 & 1.5 & 3.1 \\
\hline $\mathrm{R}-2^{\mathrm{y}}$ & 3.5 & 0.2 & 3.1 & 4.3 \\
\hline$R-3^{x}$ & 4.6 & 0.2 & 4.1 & 5.2 \\
\hline $\mathrm{R}-4^{\mathrm{w}}$ & 6.9 & 0.4 & 5.5 & 7.7 \\
\hline Rate $^{v}$ & 4.2 & 0.2 & 3.7 & 4.6 \\
\hline AUDPC & 86.9 & 3.3 & 78.0 & 96.2 \\
\hline \multicolumn{5}{|l|}{ Field 2019} \\
\hline $\mathrm{R}-1^{\mathrm{z}}$ & 4.3 & 0.5 & 1.8 & 5.5 \\
\hline $\mathrm{R}-2^{\mathrm{y}}$ & 5.4 & 0.5 & 3.3 & 6.6 \\
\hline $\mathrm{R}-3^{\mathrm{x}}$ & 6.2 & 0.5 & 4.3 & 7.6 \\
\hline $\mathrm{R}-4^{\mathrm{w}}$ & 6.7 & 0.5 & 4.4 & 8.3 \\
\hline Rate $^{v}$ & 5.6 & 0.5 & 3.5 & 6.7 \\
\hline AUDPC & 119.2 & 9.4 & 75.1 & 141.9 \\
\hline
\end{tabular}

${ }^{\mathrm{z}}$ Disease severity rating at $7 \mathrm{DAI}$.

${ }^{\mathrm{y}}$ Disease severity rating at $14 \mathrm{DAI}$.

${ }^{\mathrm{x}}$ Disease severity rating at $21 \mathrm{DAI}$.

${ }^{\mathrm{w}}$ Disease severity rating at $28 \mathrm{DAI}$.

${ }^{\mathrm{v}}$ Average disease severity rating.

AUDPC $=$ area under the disease progress curve; $\mathrm{DAI}=$ days after inoculation

produces a 216- to 224-bp fragment in all three species, $D b 06$ that produces a $283-$ to 289-bp in S. citrulli and a 268-bp and slightly fainter fragment in S. cucurbitacearum, and Db01 that produces a 256- to 364-bp fragment in S. citrulli (Brewer et al., 2015). Isolate number 3 (ISO-3), obtained from infected plants in 1998, was identified as $S$. cucurbitacearum. We used this isolate as our source of inoculum (Fig. 1).

For long-term storage (Sinclair and Dhingra, 1995), we transferred the fungus onto sterile filter paper (Whatman \#2, $70 \mathrm{~mm}$ diameter), subcultured the fungus for 2 to 4 weeks, dehydrated the filter paper disk and the mycelium for 12 to $16 \mathrm{~h}$ at room temperatures $\left(24 \pm 3{ }^{\circ} \mathrm{C}\right)$ in a sterile laminar-flow hood, cut the filter paper into squares $(5 \times$ $5 \mathrm{~mm}$ ), and stored them in sterile test tubes in a refrigerator $\left(3 \pm 1{ }^{\circ} \mathrm{C}\right)$ in the dark. Liquid cultures were grown in 1-L flasks containing $500 \mathrm{~mL}$ of $25 \%$ potato dextrose broth (PDB) and two to three plugs of PDA cultures of $S$. cucurbitacearum. The flasks containing liquid culture were incubated in a shaker at 180 $\mathrm{rpm}$ for 8 to $10 \mathrm{~d}$ at $24 \pm 2{ }^{\circ} \mathrm{C}$ under alternating periods of $12 \mathrm{~h}$ of fluorescent light $\left(40-90 \mu \mathrm{mol} \cdot \mathrm{m}^{-2} \cdot \mathrm{s}^{-1}\right.$ photosynthetic photon flux density) and $12 \mathrm{~h}$ of darkness.
For all inoculations, we filtered the liquid from each flask through four layers of sterile cheesecloth to remove dislodged agar and some mycelia. The spore concentration was measured with a hemacytometer and adjusted to a concentration of $5 \times 105$ spores $/ \mathrm{mL}$ by adding deionized water. Tween $20(0.06$ $\mathrm{g} \cdot \mathrm{L}^{-1}$ ) was added to the inoculum to keep the spores well-dispersed in the inoculum solution (Song et al., 2004). During the late afternoon of the day of inoculation, we irrigated with $\approx 12 \mathrm{~mm}$ of water to promote disease development with high relative humidity at night.

Inoculation. In the greenhouse, we inoculated plants at the second true leaf stage (2 weeks after sowing) after damaging the trichomes on the leaf surface by brushing the plants with a wooden stake $(20 \times 200 \mathrm{~mm})$. The inoculum was delivered using a handpumped spray bottle. After inoculation, we moved the plants into a humidity chamber with sides and a top made of clear polyethylene. The top was kept open during the summer and closed during the winter to keep the internal temperature close to $24{ }^{\circ} \mathrm{C}$, which is optimum for $S$. cucurbitacearum. Humidifiers were continuously run in the chamber during the treatment time (from $1 \mathrm{~d}$ before inoculation through $3 \mathrm{~d}$ after inoculation) to keep the relative humidity close to $100 \%$ day and night. Plants were watered daily using overhead sprinklers when humidifiers were not being used.

In the field, we inoculated plants when they reached the fourth true leaf stage (4 weeks after sowing), after overhead irrigation of $\approx 12 \mathrm{~mm}$ of water during the previous $2 \mathrm{~d}$ to promote guttation on the day of inoculation, and after damaging the trichomes on the leaf surface at each time before the inoculum was delivered by brushing the plants with a wooden stake $(20 \times 200 \mathrm{~mm})$ mounted on a 600-mm-long aluminum handle (Lou et al., 2013; Song et al., 2004). Plants were inoculated at least two times at 2-week intervals by spraying the inoculum on all upper leaf surfaces. We delivered the inoculum as a fine mist using a backpack sprayer operated at a pressure of 200 to $275 \mathrm{kPa}$ (30-40 psi). During the late afternoon of the day of inoculation, we irrigated with $\approx 12 \mathrm{~mm}$ of water to promote disease development with high relative humidity at night.

Data collection. Plants were rated 3 weeks after sowing ( 1 week after inoculation) in the greenhouse and when the symptoms appeared on the leaves and stems of the susceptible checks in the field ( 7 weeks after planting and 1 week after the second inoculation). In the greenhouse and the field, plants were rated for disease severity at 7 (R-1), 14 (R-2), 21 (R-3), and 28 (R-4) days after inoculation (DAI). Using these four ratings, the average disease severity rating was estimated for the greenhouse ( $\mathrm{GH}$ rate), field (field rate), and both locations (rate). The following ordinal disease assessment scale was used (Gusmini et al., 2002): $0=$ no disease; 1 = yellowing on leaves (a trace of disease only); 2 to $4=$ symptoms on leaves only; $5=$ some leaves dead, no symptoms on stem; 6 to $8=$ symptoms on leaves and stems; and $9=$ plant dead. Plants with a disease rating of 6 or greater had lesions on the stem, thus making them prone to death caused by subsequent development of disease. Plants with a disease rating of 5 or less had lesions only on the leaves. Leaf ratings are important because plant survival and yield are affected by the leaf area, which is reduced on disease-susceptible plants. Stem ratings are important because large localized lesions can kill the plant, especially if they are near the shoot apex. Additionally, we estimated the AUDPC based on the formula of Simko and Piepho (2012) as the control of the ordinal scale used in this study.

Fruit data collected were shape, rind pattern and toughness, seed size and color, flesh color and intensity, overall quality, and hollow heart according to Wehner (2008). The fruit shape was classified as elongate, oval, or round. The rind pattern was gray, narrowstriped, medium-striped, wide-striped or dark. Rind toughness was rated as follows: tender $=1$; intermediate $=5$; and tough $=9$. Seed size was classified as follows: tomato $=$ $2 ;$ small $=4 ;$ medium $=6$; and large $=8$. Seed color was classified as follows: white $=2 ; \tan =4$; brown $=6$; and black $=8$. Flesh color was classified as red, orange, salmon, canary, and white. Color intensity was classified as faded and poor $($ score $=1)$ to bright and uniform $($ score $=9)$. The overall quality was classified as poor $($ score $=1)$ to excellent $($ score $=9)$. Finally, the hollow heart was classified as none $($ score $=0)$ to severe $($ score $=9)$ (Wehner, 2008).

Statistical analysis. A randomized complete block design was used and consisted of 10 screening blocks and 3 years for the field and only 1 year for the greenhouse. In each screening block, each cultigen was replicated once. Cultigens were considered fixed, and years and locations were considered random effects in the model. An analysis of variance (ANOVA) was performed using the PROC MIXED procedure of the SAS 9.3 statistical package program (Cary, NC). The restricted maximum likelihood (REML) with and without the GROUP statement and the TYPE III test of fixed effect methods were used for a preliminary analysis of the disease severity assessment evaluated during this study. The best method was selected based on the Bayesian information criterion and Akaike's information criterion (BIC and AIC), which measure the goodness of fit for each. Therefore, the methodology that showed the lowest $\mathrm{BIC}$ and AIC were chosen as the best because they provide the correct balance between the fit to the data and model complexity. In our study, the TYPE III test of the fixed effect was the best method of determining differences in the means of RILs. Adjusted means were obtained using LSMeans of the SAS program.

Phenotypic correlations and principal component analysis (PCA). Corrected trait means (least squared means) generated after performing the ANOVA were used to estimate the possible correlation between disease severity ratings and fruit quality traits. Phenotypic correlations (Pearson's correlation) among the 


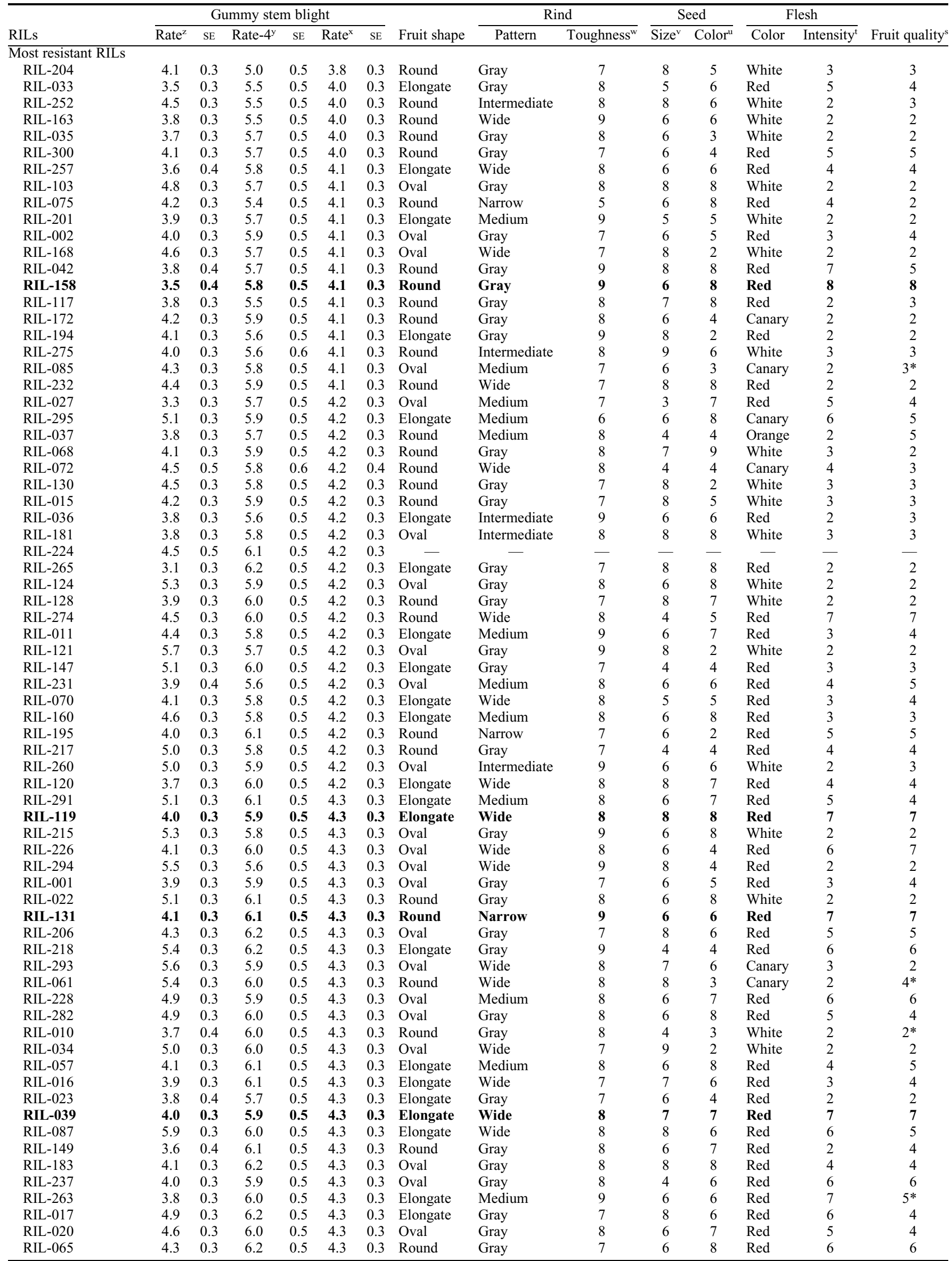


Table 4. (Continued) Average disease severity and fruit quality trait ratings of the most resistant and susceptible RILs.

\begin{tabular}{|c|c|c|c|c|c|c|c|c|c|c|c|c|c|c|}
\hline \multirow[b]{2}{*}{ RILs } & \multicolumn{6}{|c|}{ Gummy stem blight } & \multirow[b]{2}{*}{ Fruit shape } & \multicolumn{2}{|c|}{ Rind } & \multicolumn{2}{|c|}{ Seed } & \multicolumn{2}{|c|}{ Flesh } & \multirow[b]{2}{*}{ Fruit quality } \\
\hline & Rate $^{z}$ & SE & Rate- $4^{y}$ & $\mathrm{SE}$ & Rate $^{x}$ & $\overline{S E}$ & & Pattern & Toughness $^{w}$ & $\mathrm{Size}^{\mathrm{v}}$ & $\overline{\text { Color }^{\mathrm{u}}}$ & Color & Intensity $^{t}$ & \\
\hline RIL-164 & 4.7 & 0.3 & 6.1 & 0.5 & 4.3 & 0.3 & Elongate & Intermediate & 8 & 6 & 2 & White & 2 & 2 \\
\hline RIL-253 & 3.7 & 0.3 & 5.8 & 0.5 & 4.3 & 0.3 & Elongate & Gray & 9 & 8 & 8 & Red & 4 & 4 \\
\hline RIL-268 & 4.2 & 0.3 & 6.1 & 0.5 & 4.3 & 0.3 & Round & Gray & 3 & 6 & 6 & Red & 2 & 2 \\
\hline \multicolumn{15}{|c|}{ Most susceptible RILs } \\
\hline RIL-092 & 5.4 & 0.3 & 6.9 & 0.5 & 4.9 & 0.3 & Elongate & Gray & 8 & 7 & 8 & Red & 4 & 6 \\
\hline RIL-071 & 5.8 & 0.3 & 6.8 & 0.5 & 4.9 & 0.3 & Elongate & Intermediate & 5 & 9 & 8 & Red & 4 & 5 \\
\hline RIL-184 & 6.0 & 0.3 & 6.7 & 0.5 & 4.9 & 0.3 & Round & Gray & 7 & 8 & 6 & Red & 6 & $6^{*}$ \\
\hline RIL-110 & 4.5 & 0.3 & 7.0 & 0.5 & 4.9 & 0.3 & Elongate & Gray & 7 & 7 & 7 & Red & 4 & 3 \\
\hline RIL-180 & 5.7 & 0.3 & 6.7 & 0.5 & 4.9 & 0.3 & Elongate & Gray & 7 & 6 & 6 & Red & 5 & 4 \\
\hline RIL-259 & 5.5 & 0.3 & 7.0 & 0.5 & 4.9 & 0.3 & Elongate & Gray & 7 & 7 & 7 & White & 2 & 2 \\
\hline RIL-106 & 5.3 & 0.3 & 6.8 & 0.5 & 5.0 & 0.3 & Elongate & Gray & 8 & 6 & 8 & Red & 7 & $6^{*}$ \\
\hline RIL-192 & 5.4 & 0.3 & 6.9 & 0.5 & 5.0 & 0.3 & Elongate & Gray & 7 & 8 & 6 & Red & 6 & 6 \\
\hline RIL-240 & 5.4 & 0.3 & 6.8 & 0.5 & 5.0 & 0.3 & Elongate & Gray & 7 & 6 & 8 & Red & 7 & $7 *$ \\
\hline RIL-038 & 5.5 & 0.3 & 7.0 & 0.5 & 5.2 & 0.3 & Elongate & Intermediate & 8 & 8 & 8 & Red & 4 & 4 \\
\hline \multicolumn{15}{|l|}{ Control cultivars } \\
\hline PI 508443 & 3.3 & 0.4 & 4.7 & 0.6 & 3.4 & 0.3 & Oval & Gray & 8 & 4 & 4 & Red & 4 & 4 \\
\hline Allsweet & 3.7 & 0.4 & 5.6 & 0.5 & 3.5 & 0.3 & Elongate & Medium & 8 & 5 & 7 & Red & 4 & 5 \\
\hline PI 526233 & 3.5 & 0.3 & - & - & 3.6 & 0.2 & Round & Medium & 8 & 8 & 8 & White & 2 & 2 \\
\hline PI 482315 & 4.1 & 0.4 & 5.5 & 0.5 & 3.6 & 0.3 & Round & Dark & 9 & 9 & 2 & Canary & 2 & 2 \\
\hline PI 189225 & 3.8 & 0.3 & 5.9 & 0.5 & 3.6 & 0.2 & Round & Dark & 9 & 8 & 2 & White & 2 & 2 \\
\hline Calhoun_Gray & 4.7 & 0.3 & 6.4 & 0.5 & 4.0 & 0.2 & Elongate & Gray & 8 & 4 & 2 & White & 2 & 2 \\
\hline AU-Producer & 5.1 & 0.7 & 5.2 & 0.5 & 4.1 & 0.3 & Oval & Narrow & 7 & 5 & 7 & Red & 4 & 5 \\
\hline PI 279461 & 3.8 & 0.3 & 6.6 & 0.5 & 4.2 & 0.2 & Oval & Dark & 9 & 8 & 2 & White & 2 & 3 \\
\hline Mickylee & 4.4 & 0.3 & 6.7 & 0.5 & 4.3 & 0.2 & Oval & Gray & 8 & 4 & 7 & Red & 5 & 5 \\
\hline Sugar Baby & 5.4 & 0.3 & 6.6 & 0.5 & 4.5 & 0.2 & - & - & - & - & - & - & - & - \\
\hline PI 512398 & 4.1 & 0.4 & 6.3 & 0.5 & 4.5 & 0.2 & Elongate & Intermediate & 9 & 6 & 2 & White & 2 & 2 \\
\hline PI 247398 & 4.1 & 0.3 & 5.9 & 0.5 & 4.6 & 0.2 & - & - & - & 一 & - & - & - & - \\
\hline Charleston Gray & 5.9 & 0.3 & 6.4 & 0.5 & 4.8 & 0.2 & Elongate & Gray & 8 & 8 & 8 & Red & 6 & 6 \\
\hline Black Diamond & 5.4 & 0.5 & 6.1 & 0.5 & 4.9 & 0.2 & Round & Dark & 9 & 8 & 7 & Red & 4 & 5 \\
\hline PI 357678 & 6.2 & 0.7 & 6.6 & 0.6 & 5.0 & 0.4 & Round & Gray & 8 & 8 & 4 & Red & 2 & 2 \\
\hline PI 183398 & 5.9 & 0.3 & 7.0 & 0.5 & 5.6 & 0.2 & Oval & Gray & 8 & 8 & 6 & Red & 2 & 2 \\
\hline NH Midget & 5.8 & 0.3 & 6.6 & 0.6 & 5.6 & 0.2 & Round & Intermediate & 8 & 4 & 6 & Red & 2 & 3 \\
\hline PI 169286 & 6.2 & 0.5 & 6.0 & 0.6 & 5.7 & 0.3 & - & - & - & - & - & - & - & - \\
\hline$F$ value & \multicolumn{2}{|c|}{$6.9 * * *$} & \multicolumn{2}{|c|}{$2.3 * * *$} & \multicolumn{2}{|c|}{$6.5 * * *$} & - & - & - & - & - & - & - & - \\
\hline Minimum & 3.1 & 0.3 & 5.0 & 0.5 & 3.2 & 0.2 & - & - & - & - & - & - & - & - \\
\hline Maximum & 6.1 & 0.3 & 7.0 & 0.5 & 5.7 & 0.4 & - & - & - & - & - & - & - & - \\
\hline
\end{tabular}

${ }^{\mathrm{z}}$ Greenhouse gummy stem blight average rating.

${ }^{\mathrm{y}}$ Combined years gummy stem blight fourth rating.

${ }^{\mathrm{x}}$ Combined years gummy stem blight average rating

${ }^{\mathrm{w}}$ Ring toughness scale: tender $=1$; intermediate $=5$; and tough $=9$.

${ }^{\mathrm{v}}$ Seed size scale: tomato $=2 ;$ small $=4 ;$ medium $=6$; and large $=8$.

${ }^{\mathrm{u}}$ Seed color scale: white $=2$; $\tan =4$; brown $=6$; and black $=8$

${ }^{\mathrm{t}}$ Color intensity: faded/poor $=1$ to bright/uniform $=9$.

${ }^{\mathrm{s}}$ Overall quality: poor $=1$ to excellent $=9$.

*Hollow heart fruit with a scale of $1-6$ in this line, where none $=0$ and bad $=9$.

The most resistant RILs with excellent fruit quality are presented as bold text.

$\mathrm{RIL}=$ recombinant inbred line.

traits were estimated by using the PROC CORR procedure of the SAS 9.4 program.

To graphically distinguish significant relationships among traits, PCA of disease severity and fruit quality traits was performed using the PROC PRINCOMP procedure of the SAS 9.3 statistical package program.

\section{Results and Discussion}

Phenotypic evaluation. Significant differences in resistance to GSB were found in the population of RILs (Table 2). Disease severity ratings at 7 (R-1), 14 (R-2), 21 (R-3), and 28 (R-4) DAI, the estimated average disease severity ratings (rate), and AUDPC showed significant differences in the combined and per-location ANOVAs $(P<0.05)$. These results suggest that one or more RILs had high resistance to GSB. Approximately twothirds $(67 \%)$ of the RILs showed an average disease rating (rate) below the mean value of the disease severity assessment scale (4.5). This evidence suggests the presence of one or more resistant genes segregating in the GSB breeding population (Fig. 2). In Table 3, R-1 ranged from 2.2 to 3.5 in the combined location analysis, from 1.5 to 4.6 and 1.4 to 3.6 in 2017 during the greenhouse and field analysis, respectively, from 1.5 to 3.1 in 2018, and from 1.8 to 5.5 in 2019 during field observations. R-2 ranged from 3.5 to 4.9 in the combined locations analysis and from 3.0 to 6.5 and 2.7 to 4.5 in the greenhouse observations and field observations, respectively, in 2017. Regarding the observations made in the field in 2018 and 2019, this score ranged, respectively, from 3.1 to 4.3 and 3.3 to 6.6. In the combined locations analysis, R3 ranged from 4.1 to 5.6 and from 3.1 to 7.7 and 3.0 to 5.3 in the greenhouse and field analyses, respectively, in 2018; however, it ranged from 4.1 to 5.2 in 2018 and 4.3 to 7.6 in 2019. In 2017, R-4 ranged from 5.0 to 7.0 in the combined locations analysis and from 3.7 to 8.1 and 3.7 and 7.2 in the greenhouse and field observations, respectively; however, the field observations changed to between 5.5 and 7.7 in 2018 and between 4.4 and 8.3 in 2019 . The average disease severity rating (rate) ranged from 3.8 to 5.2 in the combined location analysis, from 3.1 to 6.1 in the greenhouse experiment, and from 2.9 to $4.8,3.7$ to 4.6 , and 3.5 to 6.7 in the three successive field observations, respectively. Finally, the AUDPC ranged from 78.6 to 107.7 in the combined locations analysis, from 64.9 to 128.9 in the greenhouse analysis, and from 60.9 to $99.7,78.0$ to 96.2 , and 75.1 to 141.9 in field analyses during 3 successive years, respectively. These results suggest the polygenic nature of this trait, which is consistent with a previous study performed by Gusmini et al. (2017).

In the population, 75 RILs $(25 \%$ of the population) showed average disease ratings 
Table 5. Phenotypic correlations of combined year disease severity ratings and fruit quality traits.

\begin{tabular}{|c|c|c|c|c|c|c|c|c|c|c|c|c|c|c|}
\hline Trait & $\mathrm{R}-1^{\mathrm{z}}$ & $\mathrm{R}-2^{\mathrm{y}}$ & $\mathrm{R}-3^{\mathrm{x}}$ & $\mathrm{R}-4^{\mathrm{w}}$ & Rate $^{v}$ & AUDPC & $\begin{array}{l}\text { Fruit } \\
\text { shape }\end{array}$ & $\begin{array}{c}\text { Rind } \\
\text { pattern }\end{array}$ & $\begin{array}{c}\text { Rind } \\
\text { toughness }\end{array}$ & $\begin{array}{l}\text { Seed } \\
\text { size }\end{array}$ & $\begin{array}{l}\text { Seed } \\
\text { color }\end{array}$ & $\begin{array}{l}\text { Flesh } \\
\text { color }\end{array}$ & $\begin{array}{c}\text { Flesh } \\
\text { intensity }\end{array}$ & $\begin{array}{c}\text { Fruit } \\
\text { quality }\end{array}$ \\
\hline $\mathrm{R}-1^{\mathrm{z}}$ & & $0.80 * * *$ & $0.70 * * *$ & $0.67 * * *$ & $0.84 * * *$ & $0.81^{* * *}$ & $-0.18 * * *$ & -0.02 & -0.04 & 0.12 & -0.05 & -0.1 & 0.13 & 0.10 \\
\hline $\mathrm{R}-2^{\mathrm{y}}$ & & & $0.91 * * *$ & $0.85^{* * *}$ & $0.96^{* * *}$ & $0.96^{* * *}$ & $-0.20 * *$ & -0.06 & -0.09 & $0.16^{* *}$ & 0.03 & -0.07 & 0.12 & 0.07 \\
\hline $\mathrm{R}-4^{\mathrm{w}}$ & & & & & $0.93 * * *$ & $0.93 * * *$ & $-0.17 * * *$ & -0.05 & -0.10 & 0.11 & 0.06 & $-0.13 *$ & $0.14^{*}$ & 0.10 \\
\hline Rate $^{\mathrm{v}}$ & & & & & & $0.98 * * *$ & $-0.19 * * *$ & -0.05 & -0.08 & $0.13 *$ & 0.04 & -0.1 & $0.13 *$ & 0.10 \\
\hline AUDPC & & & & & & & $-0.20 * * *$ & -0.04 & -0.09 & $0.13^{*}$ & 0.03 & -0.11 & $0.13^{*}$ & 0.10 \\
\hline Rind toughness & & & & & & & & & & -0.04 & -0.02 & 0.05 & -0.03 & -0.03 \\
\hline Seed size & & & & & & & & & & & $0.17 * *$ & $0.16^{*}$ & -0.03 & -0.07 \\
\hline Seed color & & & & & & & & & & & & $-0.19 * *$ & $0.31 * * *$ & $0.27 * * *$ \\
\hline Flesh color & & & & & & & & & & & & & $-0.53 * * *$ & $-0.53 * * *$ \\
\hline Flesh intensity & & & & & & & & & & & & & & $0.9^{* * *}$ \\
\hline
\end{tabular}

${ }^{\mathrm{z}}$ Combined years disease severity rating at 7 DAI.

${ }^{\mathrm{y}}$ Combined years disease severity rating at 14 DAI.

${ }^{\mathrm{x}}$ Combined years disease severity rating at 21 DAI.

${ }^{\mathrm{w}}$ Combined years disease severity rating at $28 \mathrm{DAI}$.

${ }^{\mathrm{v}}$ Combined years disease severity rating.

$*, * *, * * *$ Significant at $P=0.05,0.01$, or 0.001 .

$\mathrm{GH}$ rate $=$ greenhouse disease severity rating; $\mathrm{AUDPC}=$ area under the disease progress curve; $\mathrm{DAI}=$ days after inoculation.

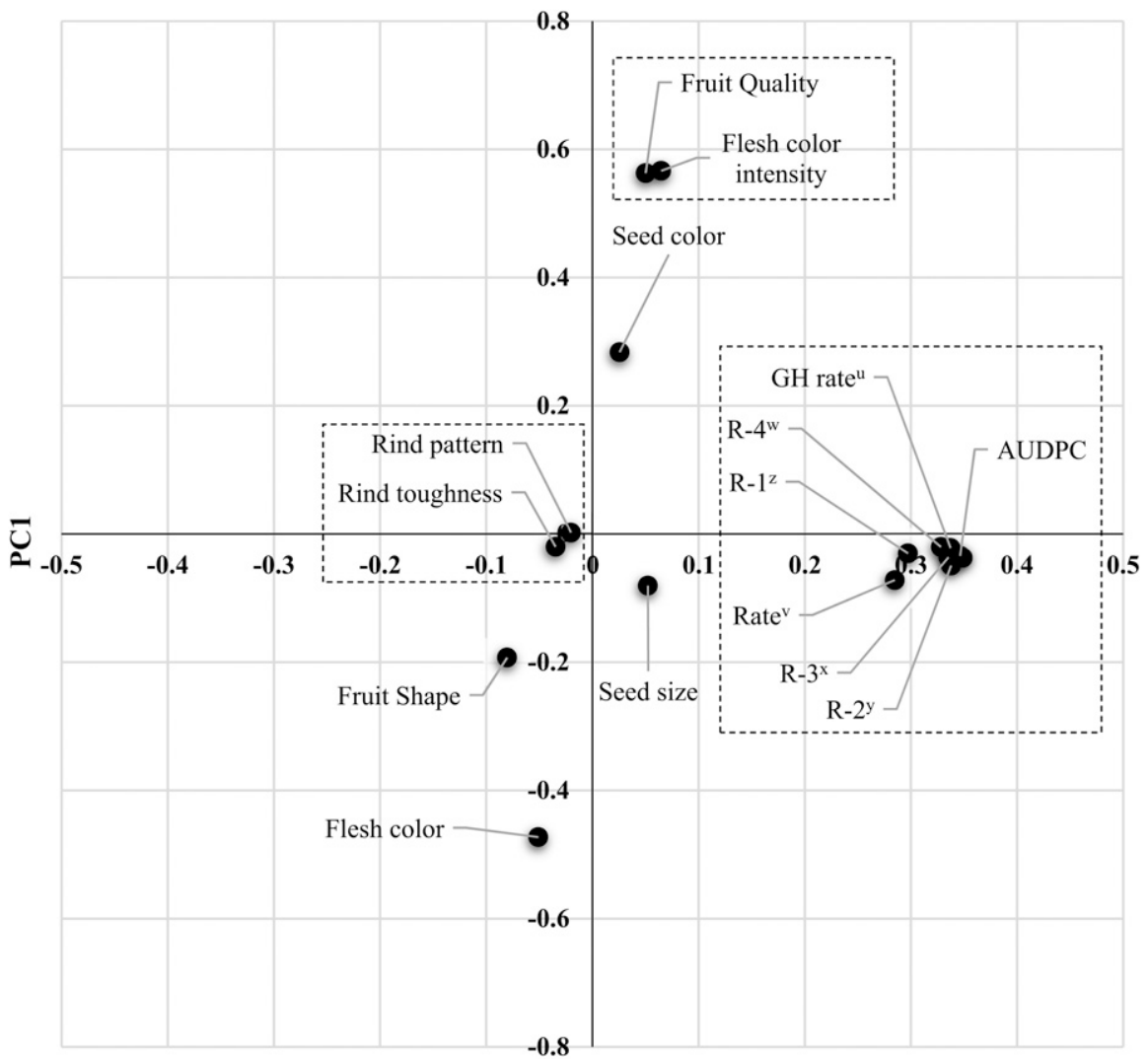

PC2

Fig. 3. Principal component analysis of disease severity and fruit quality traits of a recombinant inbred line population of watermelon. ${ }^{\mathrm{z} C}$ Combined years disease severity rating at 7 days after inoculation (DAI); ${ }^{y}$ combined years disease severity rating at $14 \mathrm{DAI}$; ${ }^{\mathrm{x}}$ combined years disease severity rating at $21 \mathrm{DAI}$; ${ }^{\mathrm{w}}$ combined years disease severity rating at $28 \mathrm{DAI}$; ${ }^{\mathrm{v}}$ combined years disease severity rating; and "greenhouse disease severity rating.

of 3.2 to 5.7 , indicating evidence of moderate to high resistance to GSB epidemics (Table 4). The most resistant of the RILs were RIL-204 (rating 3.8), RIL-033 (rating 4.0), RIL-252 (rating 4.0), RIL-163 (rating 4.0), RIL-035 (rating 4.0), and RIL-300 (rating 4.0); the most susceptible of the RILs were RIL-038 (rating 5.2), RIL-240 (rating 5.0), RIL-192 (rating 5.0), and RIL-106 (rating 5.0). The most resistant RILs were more resistant than the resistant controls (PI 508443 and Allsweet). Additionally, some of the most resistant lines showed good fruit quality for the market (Table 4). Recombinant inbred lines RIL-158, RIL-039, RIL-277, RIL131, RIL-226, RIL-119, and RIL-283 had diverse fruit shapes, rind patterns, seed sizes, and seed colors. Most importantly, they had excellent rind toughness, flesh color, and intensity, with overall fruit quality ratings from 6 to 8 . These results are evidence of the progress achieved for the GSB RILs population as enhanced germplasm to develop watermelon lines with high resistance to GSB epidemics and excellent fruit quality for the market.

Correlations among disease severity and fruit quality traits. For centuries, plant breeders have relied on phenotypic selection as a major tool of genetic gain and improvement in crops (Bernardo, 2010). Selection criteria, particularly when trying to improve several traits at once, depend on the degree to which the selection phenotype is correlated with the target phenotype. Disease severity ratings in the field and greenhouse were significantly correlated $(r=0.67)$, suggesting that in both environments the ratings were useful and consistent with the classification of the resistant and susceptible lines $(P<$ 0.001 ) (Table 5). The average disease severity rating combined over years (rate) was significantly correlated with the other disease severity ratings (R-1, R-2, R-3, R-4, GH rate, and AUDPC) $(P<0.001)$ (Table 5). Disease severity ratings showed no correlation or a weak negative correlation with most fruit quality traits, suggesting that fruit quality can be improved without losing resistance. However, fruit shape had a significant negative correlation with all traits, including all disease severity ratings; however, flesh color $(r=0.32 ; P>0.001)$ and fruit quality showed a high correlation with flesh intensity $(r=$ $0.90 ; P>0.001)$ but a negative correlation with flesh color $(r=-0.53 ; P>0.001)$.

During the PCA, the disease severity ratings ( $\mathrm{R}-1, \mathrm{R} 2, \mathrm{R}-3, \mathrm{R}-4$, rate, $\mathrm{GH}$ rate, and AUDPC) were clustered in the same group, and fruit quality and flesh color intensity were clustered in a different group 

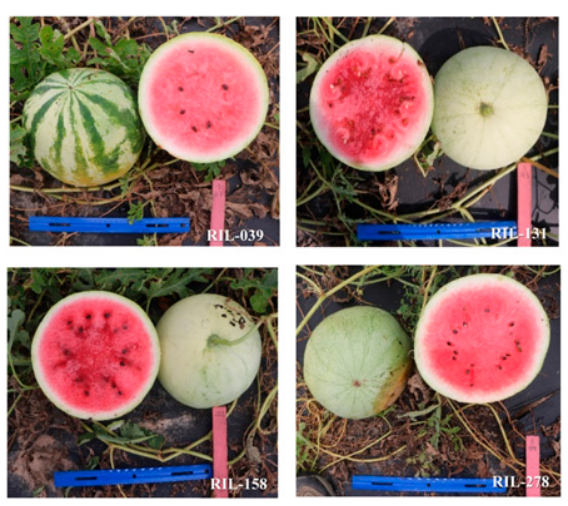

Fig. 4. Most resistant recombinant inbred lines (RILs) segregating for fruit quality traits.

(Fig. 3). Although rind pattern and rind toughness were also grouped, these traits did not have significant correlation with any of the other traits (Fig. 3; Table 5). Interestingly, seed color, seed size, fruit shape, and flesh color were isolated from the other groups. Seed color and seed size had no correlation or a weak negative correlation with the other traits, and fruit shape and flesh color had mostly negative correlations with the other traits (Fig. 3; Table 5). This study demonstrates the value of our approach. Our research focused on combining resistance genes, incorporating fruit quality traits into the population, and fixing those genes in a homozygous state in recombinant inbred lines.

Enhanced watermelon germplasm for cultivar development. In the watermelon germplasm collection, plant introductions have important genes for resistance to GSB but lack desirable fruit quality traits (Gusmini et al., 2005). The inheritance of resistance to GSB is complex, and the number of resistance genes is unknown (Gusmini et al., 2017). New breeding approaches are needed to incorporate GSB-resistant genes into single cultigens. Others have suggested several cycles of intercrossing in a population, intercrossing to elite cultivars, and then selfpollination to create lines in a homozygous state (Strange et al., 2002). In the GSB RIL population, the PI accessions (PI 482342, PI 482283, PI 189225, PI 482374, and PI 526233) contributed resistance genes and the susceptible cultivars (Charleston Gray, Calhoun Gray, Mickylee, Minilee, Allsweet, Crimson Sweet, and Petite Sweet) contributed fruit quality genes. The result of recombining (crossing and intercrossing) and fixing (self-pollination) resistance genes with fruit quality genes was a population of 300 recombinant inbred lines. Based on our results, the RIL population has moderate-tohigh resistance (with one or more genes) to GSB and variations in fruit quality traits (Fig. 4). Finally, the 11 GSB-resistant RILs that also have good fruit quality ratings are evidence of the success of that breeding approach (Gusmini et al., 2005, 2017).

Further research is needed to evaluate the inheritance of resistance to GSB in the RIL population. Molecular approaches could pro- vide important information about the location of genomic regions carrying resistance genes for GSB. Most importantly, finding molecular markers tightly linked to GSB genes could provide an excellent tool for marker-assisted selection. Finally, multi-environmental trials are also needed to determine the genetic stability of the selected RILs over years and locations.

\section{Literature Cited}

Avenot, H.F., A. Thomas, R.D. Gitaitis, D.B Langston, and K.L. Stevenson. 2012. Molecular characterization of boscalid- and penthiopyrad-resistant isolates of Didymella bryoniae and assessment of their sensitivity to fluopyram. Pest Manag. Sci. 68:645-651, doi: 10.1002/ps.2311.

Basim, E., H. Basim, M. Abdulai, D. Baki, and N. Orturk. 2016. Identification and characterization of Didymella bryoniae causing gummy stem blight disease of watermelon (Citrullus lanatus) in Turkey. Crop Prot. 90:150-156, doi: 10.1016/j.cropro.2016.08.026.

Bernardo, R. 2010. Breeding for quantitative traits in plants. Stemma Press, Woodbury, MN.

Boylan, G.E., J.D. Norton, and B.R. Abrahams. 1994. Screening for resistance to anthracnose (race 2), gummy stem blight, and root knot nematode in watermelon germplasm. Cucurbit Genet. Coop. 110:106-110.

Brewer, M.T., M. Rath, and H.X. Li. 2015. Genetic diversity and population structure of cucurbit gummy stem blight fungi based on microsatellite markers. Phytopathology 105:815-824, doi: 10.1094/PHYTO-10-14-0282-R.

Bruton, B. 1998. Soilborne diseases in Cucurbitaceae: Pathogen virulence and host resistance. Cucurbitaceae Proc. 1:143-166.

Café-Filho, A.C., G.R. Santos, and F.F. Laranjeira. 2010. Temporal and spatial dynamics of watermelon gummy stem blight epidemics. Eur. J. Plant Pathol. 128:473-482, doi: 10.1007/ s10658-010-9674-1.

dos Santos, G.R., S.C.R. Sousa, F.C. Juliatti, A.C. Rodrigues, M.S. Dalcin, and A. Bonifácio. 2016. Control of gummy stem blight in watermelon through different management systems. Biosci. J. 32:371-377.

Gusmini, G., T.C. Wehner, and G.J. Holmes. 2002. Disease assessment scales for seedling screening and detached leaf assay for gummy stem blight in watermelon. Rep. Cucurbit Genet. Coop. 25:36-40.

Gusmini, G., T.L. Ellington, and T.C. Wehner. 2003. Mass production of gummy stem blight spores for resistance screening. Cucurbit Genet. Coop. Rep. 26:26-30.

Gusmini, G., R. Song, and T.C. Wehner. 2005. New sources of resistance to gummy stem blight in watermelon. Crop Breeding. Genetics \& Cytology 45:582-588, doi: 10.2135/cropsci2005 .0582 .

Gusmini, G. and T.C. Wehner. 2006. Qualitative inheritance of rind pattern and flesh color in watermelon. J. Hered. 97:177-185, doi: 10.1093/jhered/esj023.

Gusmini, G., L.A. Rivera-Burgos, and T.C. Wehner. 2017. Inheritance of resistance to gummy stem blight in watermelon. HortScience 52:14771482, doi: 10.21273/HORTSCI12123-17.

Haejeen, B., A.R. Davis, P.O. Box, H. West, S. Kim, D.I. Leskovar, G.F. Road, and S.R. King. 2010. Flesh color inheritance and gene interactions among canary yellow, pale yellow, and red watermelon. HortScience 135:362-368, doi: 10.21273/JASHS.135.4.362.
Huang, C.J. and Y.R. Lai. 2019. First report of Stagonosporopsis citrulli causing gummy stem blight of watermelon in Taiwan. J. Plant Pathol. 101:417, doi: 10.1007/s42161-018-0192-x.

Keinath, A. 1995. Fungicide timing for optimum management of gummy stem blight epidemics on watermelon. Plant Dis. 79:354-358.

Keinath, A.P. 1996. Soil amendment with cabbage residue and crop rotation to reduce gummy stem blight and increase growth and yield of watermelon. Plant Dis. 80:564-570.

Keinath, A.P. 2016. Polyoxin D and other biopesticides reduce gummy stem blight but not anthracnose on melon seedlings. Plant Heal. Res. 17:177-181, doi: 10.1094/PHP-RS-160025 .

Kemble, J.M., I. Meadows, K. Jennings, and J. Walgenbach. 2020. Southeastern US 2020 vegetable crop handbook. North Carolina State University. $<$ https://content.ces.ncsu.edu/ southeasternus-vegetable-crop-handbook $>$.

Lee, D.H., S.B. Mathur, and P. Neergaard. 1984. Detection and location of seed-borne inoculum of Didymella bryoniae and its transmission in seedlings of cucumber and pumpkin. J. Phytopathol. 109:301-308, doi: 10.1111/j.14390434.1984.tb00723.x

Li, H.X. and M.T. Brewer. 2016. Spatial genetic structure and population dynamics of gummy stem blight fungi within and among watermelon fields in the Southeastern United States. Phytopathology 106:900-908, doi: 10.1094/ PHYTO-01-16-0006-R.

Li, H.X., K.L. Stevenson, and M.T. Brewer. 2016. Differences in sensitivity to a triazole fungicide among Stagonosporopsis species causing gummy stem blight of cucurbits. Plant Dis. 100:2106-2112, doi: 10.1094/PDIS-03-160341-RE.

Lou, L., H. Wang, C. Qian, J. Liu, Y. Bai, and J. Chen. 2013. Genetic mapping of gummy stem blight (Didymella bryoniae) resistance genes in Cucumis sativus-hystrix introgression lines. Euphytica 192:359-369, doi: 10.1007/s10681013-0860-z.

Maynard, D.N. and D.L. Hopkins. 1999. Watermelon fruit disorders. HortTechnology 9:155162, doi: 10.21273/HORTTECH.9.2.155.

Norton, J.D. 1979. Inheritance of resistance to gummy stem blight caused by Didymella bryoniae in watermelon. HortScience 14:630-632.

Norton, J.D., R.D. Cosper, D.A. Smith, and K.S. Rymal. 1986. 'AU-Jubilant' and 'AU-Producer' watermelons. HortScience 21:14601461

Norton, J.D., G.E. Boyhan, D.A. Smith, and B.R Abrahams. 1993. 'AU-Golden Producer' watermelon. HortScience 28:681-682, doi: 10.21273/HORTSCI.28.6.681.

Norton, J.D., G.E. Boyhan, D.A. Smith, and B.R. Abrahams. 1995. 'AU-Sweet Scarlet' watermelon. HortScience 30:393-394, doi: 10.21273/HORTSCI.30.2.393.

Rennberger, G., P. Gerard, and A.P. Keinath. 2018 Occurrence of foliar pathogens of watermelon on commercial farms in South Carolina estimated with stratified cluster sampling. Plant Dis. 102(11):2285-2295, doi: 10.1094/PDIS03-18-0468-RE

Rennberger, G., P. Gerard, and A.P. Keinath. 2019. Factors influencing the occurrence of foliar pathogens in commercial watermelon fields in South Carolina based on stratified cluster sampling. Plant Dis. 103(3):484-494, doi: 10.1094/ PDIS-07-18-1188-RE.

Schandry, N. 2017. A practical guide to visualization and statistical analysis of $R$. solanacearum 
infection data using R. Front. Plant Sci. 8:1-14, doi: 10.3389/fpls.2017.00623.

Sherbakoff, C.C. 1917. Some important diseases of truck crops in Florida. Florida Agr. Exp. Stn. Bull. 139:269-277.

Sherf, A.F. and A.A. MacNab. 1986. Vegetable diseases and their control. 2nd ed. John Wiley $\&$ Sons, Inc., New York.

Simko, I. and H.P. Piepho. 2012. The area under the disease progress stairs: Calculation, advantage, and application. Phytopathology 102:381-389, doi: 10.1094/PHYTO-07-11-0216.

Sinclair, J.B. and O.D. Dhingra. 1995. Basic plant pathology methods. 2nd ed. CRC Press, Boca Raton, FL.

Song, R., G. Gusmini, and T.C. Wehner. 2004. A summary of eleven preliminary studies of greenhouse and field testing methods for resistance to gummy stem blight in watermelon, $\mathrm{p}$. 301-305. In: A. Lebeda and H.S. Paris (eds.). Progress in cucurbit genetics and breeding research. Palacky University, Olomouc, Czech Republic.

Sowell, G. and G.R. Pointer. 1962. Gummy stem blight resistance in introduced watermelons. Plant Dis. Rep. 46:883-885.
St. Amand, P.C. and T.C. Wehner. 2001. Generation means analysis of leaf and stem resistance to gummy stem blight in cucumber. J. Amer. Soc. Hort. Sci. 126:95-99, doi: 10.21273/ JASHS.126.1.95.

Stewart, J.E., A.N. Turner, and M.T. Brewer. 2015. Evolutionary history and variation in host range of three Stagonosporopsis species causing gummy stem blight of cucurbits. Fungal Biol. 119(5):370 382, doi: 10.1016/j.funbio.2014.12.008.

Strange, E., N. Guner, Z. Pesic-VanEsbroeckb, and T. Wehner. 2002. Screening the watermelon germplasm collection for resistance to papaya ringspot virus type-W. Crop Sci. 42:1324 1330, doi: 10.2135/cropsci2002.1324.

Szamosi, C., I. Solmaz, N. Sari, and C. Barsony. 2009. Morphological characterization of Hungarian and Turkish watermelon (Citrullus lanatus (Thunb.) Matsum. et Nakai) genetic resources. Genet. Resources Crop Evol. 56:1091-1105, doi: 10.1007/ s10722-009-9432-4.

Thomas, A., D.B. Langston, and K.L. Stevenson. 2012. Baseline sensitivity and cross-resistance to succinate-dehydrogenase-inhibiting and demethylation-inhibiting fungicides in Didy- mella bryoniae. Plant Dis. 96:979-984, doi: 10.1094/PDIS-09-11-0744-RE.

van Steekelenburg, N.A.M. 1983. Epidemiological aspects of Didymella bryoniae, the cause of stem and fruit rot of cucumber. Neth. J. Plant Pathol. 89(3):75-86, doi: 10.1007/BF01976346.

Wehner, T.C. 2008. Watermelon, p. 381-418. In: J. Prohens and F. Nuez (eds.). Vegetables I: Asteraceae, Brassicaceae, Chenopodicaceae, and Cucurbitaceae. Springer New York, NY.

Yuen, J.E. and G.A. Forbes. 2009. Estimating the level of susceptibility to Phytophthora infestans in potato genotypes. Phytopathology 99:782-786, doi: 10.1094/PHYTO-99-6-0782.

Zhang, J., S. Guo, Y. Ren, H. Zhang, G. Gong, M. Zhou, G. Wang, M. Zong, H. He, F. Liu, and Y. Xu. 2017. High-level expression of a novel chromoplast phosphate transporter ClPHT4;2 is required for flesh color development in watermelon. New Phytol. 213:1208-1221, doi: 10.1111/nph.14257.

Zitter, T.A. and C.E. Thomas. 1996. Compendium of Cucurbit diseases. American Phytopathological Society Press, St. Paul, MN. 